\title{
PARTURITION DIFFICULTIES IN SHEEP
}

\author{
F.J. GROMMERS, L. ELVING and P. VAN ELDIK \\ Department of Animal husbandry, Faculty of Veterinary Medicine, University of Utrecht, \\ P.O. Box 80.156, 3508 TD Utrecht (The Netherlands)
}

(Accepted 4 February 1985)

\section{ABSTRACT}

Grommers, F.J., Elving, L. and Van Eldik, P., 1985. Parturition difficulties in sheep. Anim. Reprod. Sci., 9: 365-374.

The incidence of difficult parturition was recorded in Texel Sheep lambs (224), Milk Sheep lambs (273) and various crossbreeds (1043) in ten spring lambing seasons. At lambing time the ewes were under 24-hour observation.

Difficult parturition is defined as necessity for obstetrical assistance as a result of failure of expulsion or progress within a given time limit.

The course of parturition was recorded on a standard protocol. Shortly after parturition ewes and lambs were weighed and several body measurements of the lambs were taken.

In this first report of the study, special attention is given to the influence of presentation of the lambs at birth. Presentation type is divided into four categories:

- stretched: upright cranial presentation with forelegs stretched in all joints (nose of lamb at upper end of metacarpus)

- shoulder-elbow flexion: upright cranial presentation with flexion of forelegs in shoulder and elbow (nose of lamb at the hooves)

- various abnormal cranial presentations

- posterior presentations

Records from 1540 lambs became available. For $284(18.4 \%)$ presentation was unknown, partly due to rapid delivery. Stretched presentation was observed in 172 $(11.2 \%)$ lambs. No lamb in this category needed assistance at birth. Shoulder-elbow flexion occurred in $707(45.9 \%)$ lambs, of which $36.9 \%$ needed assistance. The incidence as well as need of assistence in this presentation increased rapidly with birthweight of the lamb. Various abnormal cranial presentations were noted in $289(18.8 \%)$ lambs, $50.9 \%$ needed assistance. Posterior presentation was seen in $88(5.7 \%)$ lambs, of which $64.8 \%$ needed assistance at birth.

For the statistical analysis of the data a stepwise logistic regression analysis was used. The significant factors influencing the incidence of difficult parturition in this study were in order of decreasing importance: (1) presentation of lamb, (2) birthweight, (3) number of lambs per ewe, (4) genetic type or breed, (5) parity of the ewe, (6) birthweightpresentation interaction, (7) genotype-presentation interaction, (8) sex of lamb.

The distinction between stretched and shoulder-elbow flexion presentation is discussed and related to results of other investigations. It is concluded that cranial presentation with forelegs stretched in all joints is the most optimal (however infrequent) presentation. 


\section{INTRODUCTION}

Parturition problems as a cause of lamb losses are well documented (Macleod et al., 1983; Wiener et al., 1983; Woolliams et al., 1983a, b), and are one of the main causes of death in lambs. Comparison of the results of the various studies is nevertheless difficult since the outcome of the studies is biased by differences in techniques used and lack of uniformity of definitions and criteria used for assistance, i.e. interference at lambing (Grommers, 1967; Naaktgeboren et al., 1971; Krueger and Wassmuth, 1974; George, 1975, 1976; Bosc and Cornu, 1976; Woolliams et al., 1983a).

The aim of the present investigation was to examine the incidence and causes of difficult parturition in sheep under intensive observation with application of standard rules regarding assistance at parturition. Special attention is given to the presentation of lambs at birth.

This first report deals with the incidence and comparative analysis of causes of difficult parturition.

\section{MATERIALS AND METHODS}

Purebred Texel Sheep and Friesian Milk Sheep were assembled at the University experimental farm. Crossbreeding of these breeds took place at the experimental farm. Additional rams were acquired if necessary to prevent inbreeding. Data were obtained from ten spring lambing seasons from 1970 to 1982, for purebred Texel Lambs in the first three years, and for crossbreds and purebred Milk Sheep thereafter.

The ewes were housed from about one week prior to the expected lambing date. Hay, silage and concentrate supplements were given according to requirements. Each ewe remained in the group until her parturition was completed. She was then put in a separate small pen together with her lambs.

During all lambing seasons the ewes were under 24-hour observation. Notes on the course of parturition were made on a standard protocol. The observers had strict instructions not to disturb a ewe in labour unless assistance proved to be necessary according to the applied rules.

Obstetrical help was given where:

(1) expulsion of the first lamb did not occur within $2 \mathrm{~h}$ of parts of the lamb appearing at the vulva; or in the case of the ewe failing to progress with the birth process the limit was $1 \mathrm{~h}$,

(2) birth of subsequent lambs was taking longer than $1 \mathrm{~h}$.

Difficult parturition was defined as necessity for assistance at birth according to the above rules.

Stretched presentation was defined as upright cranial presentation with forelegs stretched in all joints and presentation of head with the forelegs. If the forelegs are stretched in all joints then the hooves of the lamb are at least $10 \mathrm{~cm}$ ahead of the nose of the lamb at the time of appearance of the nose in the vulva. 
Shoulder and elbow flexion was defined as upright cranial presentation with head and both forelegs in the birth canal but with both forelegs flexed in shoulder and elbow, resulting in a position where the nose is above the hooves.

Various abnormal cranial presentations comprise all cranial presentations other than the above presentations, i.e. deviation of head and neck and/or one or both forelegs flexed in any joint or retained (Roberts, 1971).

Posterior presentation includes all presentations of lambs where hind parts are born first, regardless of posture.

Stillbirth was defined as death of the lamb at parturition or within $24 \mathrm{~h}$ of birth.

Lambs were weighed after licking by the ewe but before sucking. Various body measurements of the lambs were taken within two days of birth. The ewes also were weighed within two days. Usually the ewes and their lambs were removed from their individual pens and regrouped at two or three days after parturition.

Some additional observations were made in a private flock of Dutch Heath Sheep.

The results of this investigation are outlined by surveys of overall influences of the most important factors (Tables 2 to 6) as shown by application of a stepwise logistic regression analysis (Biomedical Programs - BMDP - 1981 edition). Statistical analysis of single factors, although of limited value in such a multifactorial process, was done with Pearsons Chi-squared test.

\section{RESULTS}

Over the ten lambing seasons, records were obtained from purebreds and their crosses in numbers as shown in Table 1. The differences in age of the primiparous ewes reflect the differences in age at puberty of the breeds and the mating policies under practical circumstances.

Complete records of 1540 lambs became available. The presentation of these lambs at birth and the percentage difficult parturition for each presentation type is summarized in Table 2. Shoulder and elbow flexion was observed in $45.9 \%$ of all the lambs in this study. For 284 lambs, presentation was unknown or not certain. This was mainly due to a rapid delivery or escape from observation.

Table 3 presents the percentage difficult parturition of the remaining 1256 lambs arranged by birthweight. The incidence of difficult parturition in these births was on average $37 \%$, with a marked increase with birthweight.

The portion of lambs with presentation in shoulder-elbow flexion showed a sharp increase from $30.3 \%$ in the lowest weight class to $77.6 \%$ in the highest weight class. The incidence of various abnormal cranial presentations was almost the same for all weight classes, stretched presentations decreased slightly with weight class, but posterior presentation decreased rapidly with weightclass. 


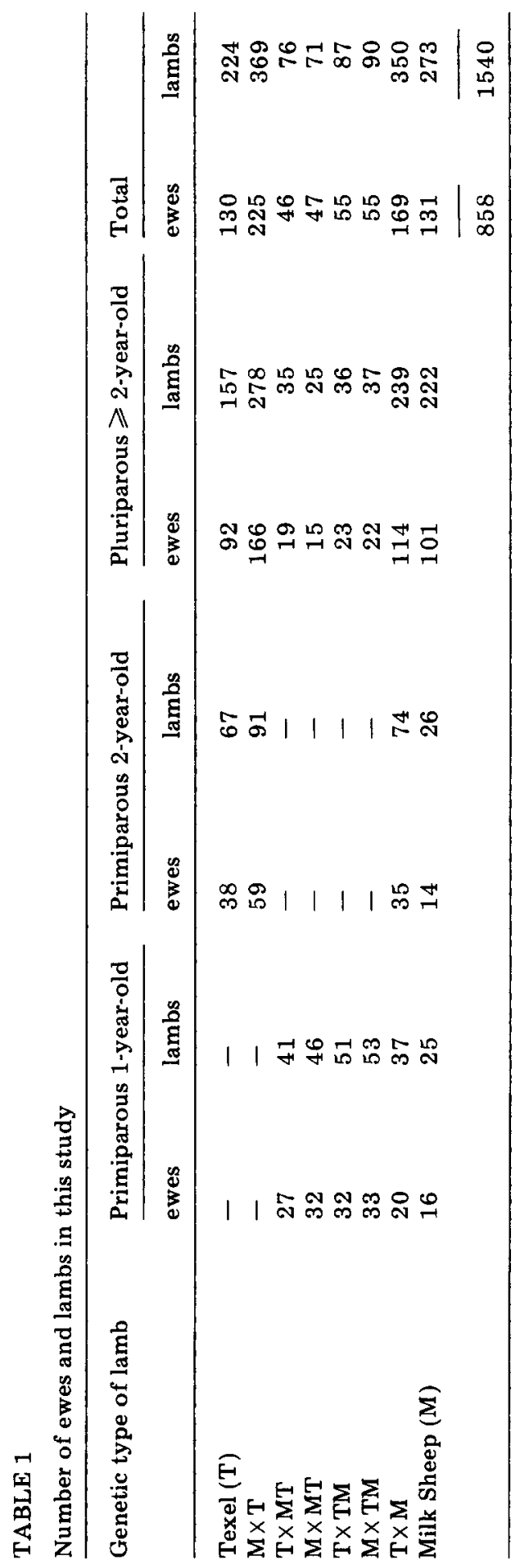


TABLE 2

Presentation of lambs overall

\begin{tabular}{|c|c|c|c|c|}
\hline \multirow[t]{2}{*}{ Presentation } & \multicolumn{2}{|c|}{ Total lambs } & \multicolumn{2}{|c|}{$\begin{array}{l}\text { Difficult } \\
\text { parturition }^{a}\end{array}$} \\
\hline & no. & $\%$ & no. & $\%$ \\
\hline Not observed (or not recorded) & 284 & 18.4 & 25 & 8.8 \\
\hline Stretched cranial & 172 & 11.2 & 0 & 0 \\
\hline Shoulder-elbow flexion & 707 & 45.9 & 261 & 36.9 \\
\hline Various abnormal cranial & 289 & 18.8 & 147 & 50.9 \\
\hline \multirow[t]{2}{*}{ Posterior } & 88 & 5.7 & 57 & 64.8 \\
\hline & 1540 & & & \\
\hline
\end{tabular}

${ }^{a}$ Differences in incidence of difficult parturition between categories are significant $(P<0.001)$.

As it is likely that most of the heavier lambs were single born, it is not surprising that the incidence of difficult parturition was two to threefold higher in single-born lambs than in twins, triplets or quadruplets (Table 4). As was already evident from Table 3 , the increased pectoral diameter caused by flexion of shoulder and elbow poses a serious difficultly on delivery of the single-born lamb.

Pluriparous ewes showed about 10\% fewer parturition difficulties than primiparous ewes (Table 5), whereas there was practically no difference between primiparous ewes of one or two years of age.

A breakdown of difficult parturition by genetic type or breed of the lamb and presentation of the lamb is restricted to pluriparous ewes (Table 6). This table shows that pluriparous Milk Sheep have about one-third of the parturition problems of Texel Sheep. For both breeds there was an increase in difficult parturition if ewes were mated by a ram of the other breed. If these crossbred ewes were mated by a ram of either breed, an intermediate level of parturition problems was observed. Differences between F2 crossbred lambs were not significant.

Tables 2 to 6 show that difficult parturition was never observed in lambs in stretched presentation, i.e. cranial presentation with forelegs stretched in all joints. Flexion of forelegs in shoulder and elbow was associated with difficult parturition most markedly with increasing birthweight (Table 3) and in ewes of the Texel breed (Table 6) that give birth to a purebred or crossbred lamb ( $\mathrm{T}$ and $\mathrm{MT}$ ).

In 25 Texel Sheep we attempted to determine whether the shoulderelbow flexion existed in earlier stages of delivery. Shortly after rupture of the fetal membranes the position of the head (nose) and forelegs (hooves) of the lamb was located while the ewe was standing and showed no abdominal contractions. 


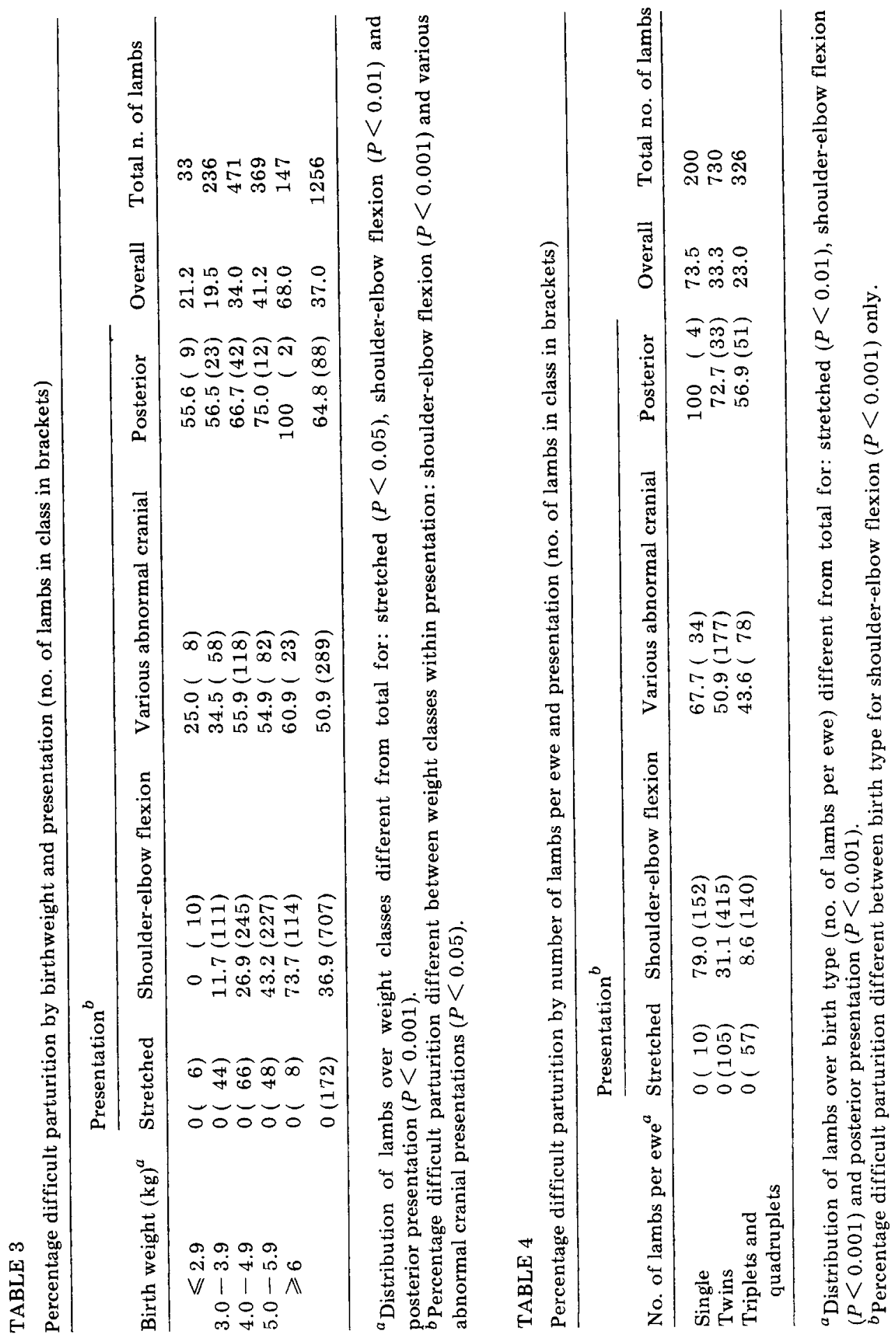



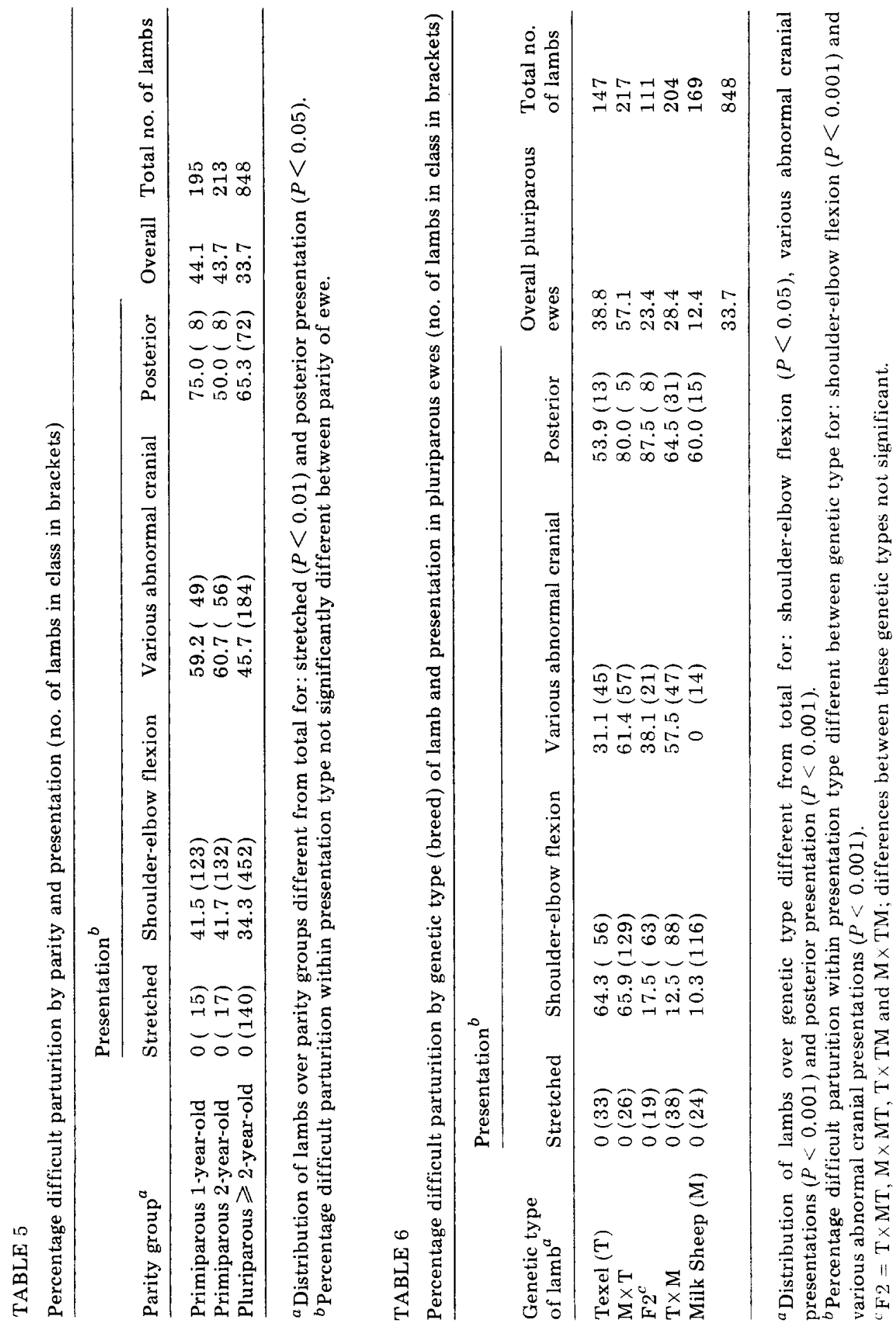
Eight lambs had already entered the pelvic inlet, one lamb being in a stretched presentation and five with shoulder-elbow flexion. All six were born with forelegs in shoulder-elbow flexion. The two other lambs showed left-right differences and/or other deviations.

Seventeen lambs were at the time still cranial of the pubic brim: six with shoulderelbow flexion and three with stretched forelegs. One was born stretched, the other eight with forelegs in shoulder-elbow flexion. Eight other lambs showed left-right differences and/or deviations.

The stepwise logistic regression analysis offers the possibility of ranking the contributing factors of difficult parturition in order of importance. The statistically significant influence of these factors (all $P<0.001$ ) in order of decreasing importance proved to be:

(1) presentation of lamb other than stretched

(2) birthweight

(3) number of lambs per ewe in that pregnancy

(4) genetic type or breed

(5) parity of ewe

(6) birthweight-presentation interaction

(7) genetic type-presentation interaction

(8) sex of lamb.

If relative birthweight (weight of lamb as \% of weight of ewe) was introduced into this programme, then the influence of parity was not statistically significant. There was a non-significant tendency toward a higher incidence of difficult parturition in first-born lambs as compared with second-born lambs.

\section{DISCUSSION}

For the genetic types listed in Table 6 the data were sampled in three or four seasons, except for the F2 lambs (two seasons). In our opinion the data are therefore biased very little by possible year effects.

The available information from the literature on the distinction between stretched presentation and shoulder-elbow flexion as well as on its consequences is confusing. Handbooks on obstetrics (Roberts, 1971; Baier and Schaetz, 1981) state that it is a cause of dystocia which can easily be corrected by slight repulsion of the fetus and traction (stretching!) on the limbs one by one. Fraser and Terhune (1977) are of the opinion that forelegs flexed in shoulder and elbow is a natural birth posture. The illustrations in their paper, which are drawings from radiographs of lambs in the birth canal, indeed show this posture clearly. Gunn (1968) considers a normal presentation "head and both fore-feet together with the feet leading". Judging from his data it is unlikely that this definition covers our description of fully stretched forelegs. Even in the case of shoulder-elbow flexion, the toes of the feet are often 1 or $2 \mathrm{~cm}$ ahead of the nose of the lambs.

Naaktgeboren et al. (1971) and Krueger (1972) define normal presenta- 
tion as upright cranial presentation with stretched forelegs. In the data of Krueger (1972), shoulder-elbow flexion is the most frequent abnormal presentation causing difficult parturition. Naaktgeboren et al. (1971), however, reported only 7 out of 197 Texel Lambs in this posture and 111 in a stretched posture. It is unlikely that their observations are correctly classified. This criticism is supported by the fact that they also observed Heath Sheep and noted only 3 shoulder-elbow flexions in 97 lambs of that breed. Some ten years after Naaktgeboren et al. (1971), we observed the course of parturition in the same flock of Heath Sheep and found shoulderelbow flexion in 19 out of 26 lambs. Our observations on Heath Sheep are in accordance with those of Naaktgeboren et al. (1971) in that over $90 \%$ of the Heath Sheep lambs do not need assistance at birth despite their birth presentation.

In this context it is remarkable that in the pluriparous ewes in our study (Table 6) the number of lambs in shoulder-elbow flexion is high in purebred Milk Sheep (116 out of 169 , i.e. $68.6 \%$ ) with a low incidence of difficult parturition $(10.3 \%)$ whereas in purebred Texel Sheep the portion of lambs in this posture is lower (56 out of 147 , i.e. $38.1 \%$ ) but with a higher incidence of difficult parturition (64.3\%).

The reason for breed differences in percentage difficult parturition due to shoulder-elbow flexion may be found in differences in the width of the pelvic inlet or the diameter of the pelvic passage. Naaktgeboren et al. (1971) found that Heath Sheep in comparison with Texel Sheep had a smaller conjugate diameter as well as a smaller transverse diameter (both near $10 \%$ ). The average birthweight of Heath Sheep, however, was only $2.7 \mathrm{~kg}$ and in Texel Sheep $4.5 \mathrm{~kg}$. Quinlivan (1971) and Fogarty and Thompson (1974) proved also that internal pelvic dimensions are important in explaining parturition difficulties. McSporran and Fielden (1979) confirmed this in radiographic studies and they conclude that incompatibility in size between maternal pelvis and the lamb is largely responsible for the need for assistance at birth.

From our observations it is obvious that shoulder-elbow flexion adds to this incompatibility (Table 3 ).

The influence of relative birthweight, shape and size of pelvic inlet and measurements of lambs will be discussed in a separate paper.

The causes of shoulder-elbow flexion may be primary or secondary. Our vaginal palpations and the portion of lambs in different weight classes (Table 3) suggest that some lambs did not stretch their forelegs at all, but that stretched legs may be forced into a flexed position due to disproportionality of the birth canal. It is noteworthy that lambs with stretched forelegs are born in all weight classes and that no lamb in this presentation category needed assistance. The data presented lead to the conclusion that shoulderelbow flexion of the forelegs has to be distinguished from stretched presentation. Upright cranial presentation with stretched forelegs in all joints is biologically the most ideal presentation in view of ease of parturition and therefore has to be regarded as the only normal presentation type. 


\section{ACKNOWLEDGEMENTS}

This investigation was supported by the Dutch Organisation for Applied Science (TNO). The assistance of the many observers and the staff of the experimental farm is gratefully acknowledged. Dr. J.A.J. Faber is thanked for his advice on the analysis of the data and Mr. A.H. Visscher and Dr. K. Carlstead for their comments on the manuscript.

\section{REFERENCES}

Baier, W. and Schaetz, F. (Editors), 1981. Tierärztliche Geburtskunde. Ferdinand Enke Verlag, Stuttgart, $150 \mathrm{pp}$.

Bosc, M.J. and Cornu, C., 1976. Etude des facteurs affectant les conditions de mise-bas et al survie des agneaux. Journ. Rech. Ovine Caprine, Inra-Itovic, 306.

Fogarty, N.M. and Thompson, J.M., 1974. Relationship between pelvic dimensions, other body measurements and dystocia in Dorset Horn ewes. Aust. Vet. J., 50: 502-506.

Fraser, A.F. and Terhune, M., 1977. Radiographic studies of postural behaviour in the sheep fetus. II. Complex fetal movements. Appl. Anim. Ethol., 3: 235-246.

George, J.M., 1975. The incidence of dystocia in fine wool Merino ewes. Aust. Vet. J., 51: $262-265$.

George, J.M., 1976. The incidence of dystocia in Dorset Horn ewes. Aust. Vet. J., 52 : 519-523.

Grommers, F.J., 1967. A preliminary study of the actual and potential perinatal lamb mortality in Texel sheep. Tijdschr. Diergeneeskd., 92: 222-233 (in Dutch, with English abstract).

Gunn, R.G., 1968. A note on difficult birth in Scottish Hill flocks. Anim. Prod., 10: $213-215$.

Krueger, D., 1972. Untersuchungen über das Auftreten von Dystokien bei Schafen verschiedener Rassen und Rassenkreuzungen. Dissertation, Universität Giessen.

Krueger, D. and Wassmuth, R., 1974. Untersuchungen über den Schwergeburten-anteil verschiedener Schafrassen und Rassenkreuzungen Z. Tierz. Züchtungsbiol., 91: $138-144$.

Macleod, N.S.M., Wiener, G. and Woolliams, C., 1983. The effects of breed, breeding system and other factors on lamb mortality. 4. Factors influencing the incidence of infectious and non-infectious diseases as causes of death. J. Agric. Sci., Camb., 100: $571-580$.

McSporran, K.D. and Fielden, E.D., 1979. Studies on dystocia in sheep. II. Pelvic measurements of ewes with histories of dystocia and eutocia. N.Z. Vet. J., 27: 75-78.

Naaktgeboren, C., Bakker-Slotboom, M.F., Van Maren, M.J. and Stegeman, J.H.J., 1971. Parturition in Texel sheep and Heath sheep, a contribution on the influence of domestication on birth. Z. Tierz. Zuchtungsbiol., 88: 169-182 (in German, with English abstract).

Quinlivan, T.D., 1971. Dystocia in sheep: preliminary observations on within and between breed differences in various sk eletal measurements. N.Z. Vet. J., 19: 73-77.

Roberts, S.J., 1971. Veterinary Obstetrics and Genital Diseases. 2nd edn. S.J. Roberts, Ithaca, NY.

Wiener, G., Woolliams, C, and Macleod, N.S.M., 1983. The effects of breed, breeding system and other factors on lamb mortality, 1. Causes of death and effects on the incidence of losses. J. Agric. Sci., Camb., 100: 539-551.

Woolliams, C., Wiener, G. and Macleod, N.S.M., 1983a. The effects of breed, breeding system and other factors on lamb mortality. 2. Factors influencing the incidence of delayed birth, dystocia, congenital defects and miscellaneous causes of early death. J. Agric. Sci., Camb. 100: 553-561.

Woolliams, C., Wiener, G. and Macleod, N.S.M., 1983b. The effect of breed, breeding system and other factors on lamb mortality. 3. Factors influencing the incidence of weakly lambs as a cause of death. J. Agric. Sci., Camb., 100:563-570. 